\title{
Severe adult-onset atopic dermatitis mistaken for cutaneous T-cell lymphoma in a medically complex patient
}

\author{
Colin Andrew Hinkamp 두, Surbhi Gupta 다, Neil Keshvani
}

Internal Medicine, University of Texas Southwestern, Dallas, Texas, USA

Correspondence to Dr Colin Andrew Hinkamp; hinkamp.colin@gmail.com

Accepted 22 February 2020

\section{DESCRIPTION}

A 45-year-old previously healthy man presented to the hospital with acute left foot pain with numbness, coldness, blue discoloration, a blackened third toe and chills for 4 days. Over the last year, he had the onset of a whole-body pruritic rash and unintentional $25 \mathrm{~kg}$ weight loss. He denied any history of allergies, food sensitivities, asthma, hay fever, atopic dermatitis or childhood rashes. He was a pack-a-day smoker and denied alcohol use. His cousin had lymphoma.

On examination, he was afebrile, tachycardic to 140 beats/min, and hypotensive to $98 / 65 \mathrm{~mm} \mathrm{Hg}$. He was ill appearing with diffuse xerosis and lichenified, erythematous, scaly plaques of the extremities, back, chest and abdomen with overlying excoriations, erosions and secondary crusting (figure 1). His left foot was cyanotic, tender and pulseless with gangrene of the third digit. Notable labs included albumin of $1.3 \mathrm{~g} / \mathrm{L}$, leucocytosis to $17 \times 10^{9} / \mathrm{L}$ and lactate of $3.2 \mathrm{mmol} / \mathrm{L}$. CT-angiogram with 3 -vessel run-off in the left lower extremity revealed mediastinal, para-aortic and bilateral axillary and inguinal lymphadenopathy, and non-visualisation of the anterior, posterior tibial and common peroneal arteries and numerous non-occlusive calcified and non-calcified thrombi within the lumens of the infrarenal abdominal aorta, common iliac artery and left common femoral artery. He subsequently underwent below-the-knee amputation with rapid improvement on antibiotics, and was started on anticoagulation and aspirin for the numerous atherothrombi.

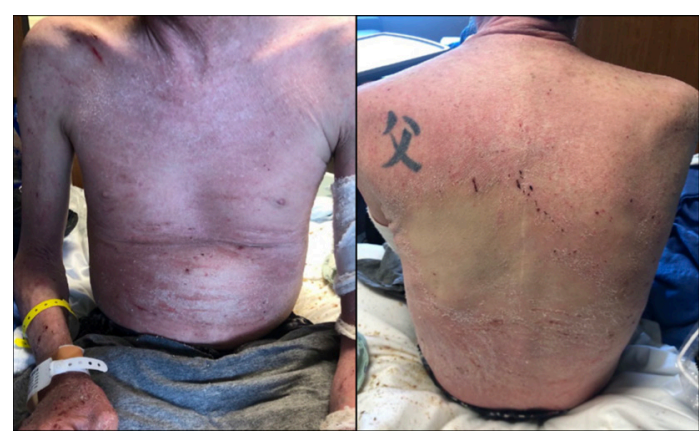

Figure 1 Diffuse xerosis with lichenified, hyperpigmented scaly plaques throughout his neck with erythema of the upper and lower back, chest and abdomen. He had multiple linear excoriations with some erosions and secondary crusting on the arms, legs, back, chest and abdomen.

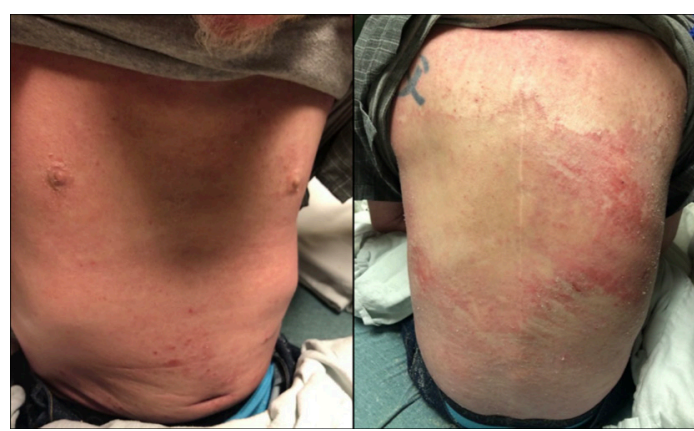

Figure 2 Skin examination after 6 months of therapy with two times per day triamcinolone $0.1 \%$ ointment with emollient, wet wraps, and mycophenolate-mofetil. there is a moderate improvement in the diffuse xerosis, Lichenification, scaly plaques and linear excoriations diffusely seen on the initial presentation.

A malabsorptive process was suspected due to severe hypoalbuminaemia, weight loss and deficiencies of folate, selenium, zinc and multiple vitamins which could have contributed to the rash. Duodenal biopsies revealed scalloping and atrophic mucosa, but MR enterography revealed no small bowel inflammation. Liver ultrasound revealed heterogeneous parenchyma with a nodular contour and ascites, suggesting chronic liver disease.

The arterial thrombosis responsible for the patient's cyanotic and gangrenous foot, as well as the severe rash, weight loss and diffuse lymphadenopathy raised concern for malignancy, particularly a cutaneous T-cell lymphoma (CTCL). A primary immunodeficiency may also account for the rash, weight loss and lymphadenopathy, although immunoglobulin levels and flow cytometry were normal. Punch biopsy showed spongiotic dermatitis, consistent with atopic dermatitis. He started topical triamcinolone $0.1 \%$ ointment and emollients with wet wraps. However, due to concern for poor daily compliance was instead given mycophenolate mofetil. Six months later, he had moderate improvement of his rash (figure 2).

Atopic dermatitis, or eczema, affects 3\%-7\% of adults in the USA. ${ }^{1}$ It is an inflammatory, spongiform dermatitis with a pruritic, erythematous, scaly rash affecting flexural surfaces that often begins in childhood, holding a relapsing-remitting course. ${ }^{2}$ In childhood it begins as weeping vesicles, progressing to dry, scaling papules and plaques, finally becoming lichenified, hypertrophied plaques from scratching. ${ }^{3}$ The presentation of 
adult-onset eczema is more heterogenous, with wider variation in lesion morphology and distribution, including higher rates of nummular and prurigo lesions and less involvement of classic flexural surfaces. ${ }^{45}$ Histology of acute lesions exhibits spongiosis, subacute lesions show acanthosis and hyperkeratosis, while chronic lesions demonstrate lichenification. ${ }^{6}$ Mainstays of treatment include topical corticosteroids, but more severe cases may require phototherapy or systemic immunosuppression to achieve adequate disease control. Dupilumab, a monoclonal antibody against the shared receptor alpha-subunit for interleukin (IL)-4 and IL-13, may also be used.

Mycosis fungoides, a subtype of CTCL, is a progressive condition characterised by fine, wrinkly, cigarette-paper scales forming scaly, erythematous plaques. ${ }^{7}$ A study of 22 patients who were diagnosed with CTCL after disease progression on tumour necrosis factor (TNF)-alpha inhibitors found that $75 \%$ of patients were being treated for presumed inflammatory skin conditions, most frequently psoriasis or eczema. Of these, 15 had biopsies consistent with the initial misdiagnosis. ${ }^{8}$ Thus, the overlap between inflammatory skin disorders and CTCL can be

\section{Patient's perspective}

It keeps itching and itching and I just have to scratch it. Then my skin flakes off if I don't apply the ointment and wraps. I hate those wraps. Imagine sleeping in wet pyjamas every night. I feel like a greased-up pig.

\section{Learning points}

- Severe atopic dermatitis can mimic uncommon diseases including cutaneous T-cell lymphomas (CTCL), primary immunodeficiencies and nutritional deficiencies. Skin biopsies may be misleading in patients with CTCL and can look similar to psoriasis or atopic dermatitis.

- Moderate-to-severe atopic dermatitis can be treated with medium-to-high potency topical corticosteroids. More severe cases may require phototherapy, systemic immunosuppression or dupilumab, a monoclonal antibody against the shared receptor alpha-subunit for IL-4 and IL-13, to achieve adequate disease control.

- Medical complexity alone does not increase the base-rate of rare diseases. This may introduce cognitive bias into the investigative process, possibly leading to unnecessary invasive testing or expenditures. clinically significant. Malignancies, including lymphomas, are associated with increased risk of thrombotic complications; the estimated incidence of thrombosis in patients with cancer who did not undergo chemotherapy is roughly four times that of the general population. ${ }^{9}$ Additionally, patients with severe atopic dermatitis may exhibit diffuse reactive lymphadenopathy related to widespread inflammation which may prompt some physicians to expand their investigation.

This patient who presented with a diffuse erythematous rash, diffuse lymphadenopathy, weight loss and an arterial thrombosis initially appeared to have CTCL. The severity of his presentation drove an exceptionally comprehensive investigation, but ultimately established the diagnosis of atopic dermatitis, illustrating that even the most medically complex patients can suffer from the most common ailments. His liver disease, vasculopathy and malnutrition remain unexplained but are thought to be unrelated. He has follow-up scheduled with vascular surgery, gastroenterology, hepatology and haematology.

Contributors $\mathrm{CAH}$, the first author, participated as the primary author of the manuscript, analysis and interpretation of data, final approval of the version published and treatment of the patient. SG participated as a major contributor to the drafting of the manuscript, providing major revisions to the draft as necessary, analysis and interpretation of data, and final approval of the version published. NK participated by providing major revisions to the draft as necessary, analysis and interpretation of data, and final approval of the version published.

Funding The authors have not declared a specific grant for this research from any funding agency in the public, commercial or not-for-profit sectors.

Competing interests None declared.

Patient consent for publication Obtained.

Provenance and peer review Not commissioned; externally peer reviewed.

\section{ORCID iDs}

Colin Andrew Hinkamp http://orcid.org/0000-0001-6047-883X

Surbhi Gupta http://orcid.org/0000-0002-4788-6596

\section{REFERENCES}

1 Sacotte R, Silverberg JI. Epidemiology of adult atopic dermatitis. Clin Dermatol 2018;36:595-605

2 Brown SJ. Atopic eczema. Clin Med 2016;16:66-9.

3 Avena-Woods C. Overview of atopic dermatitis. Am J Manag Care 2017;23:S115-23.

4 Silverberg JI, Dermatitis A-OA. Adult-Onset atopic dermatitis. J Allergy Clin Immunol Pract 2019:7:28-33.

5 Silvestre Salvador JF, Romero-Pérez D, Encabo-Durán B. Atopic dermatitis in adults: a diagnostic challenge. J Investig Allergol Clin Immunol 2017;27:78-88.

6 Bolognia JS, Cerroni J, Dermatology L. 4Th ED. Philadelphia: Elsevier, 2018.

7 Pulitzer M, Lymphoma CT-cell. Cutaneous T-cell lymphoma. Clin Lab Med 2017; 37:527-46.

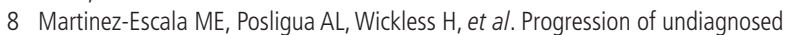
cutaneous lymphoma after anti-tumor necrosis factor-alpha therapy. J Am Acad Dermatol 2018;78:1068-76.

9 Heit JA, Silverstein MD, Mohr DN, et al. Risk factors for deep vein thrombosis and pulmonary embolism. Arch Intern Med 2000;160:809-15.

Copyright 2020 BMJ Publishing Group. All rights reserved. For permission to reuse any of this content visit

https://www.bmj.com/company/products-services/rights-and-licensing/permissions/

BMJ Case Report Fellows may re-use this article for personal use and teaching without any further permission.

Become a Fellow of BMJ Case Reports today and you can:

- Submit as many cases as you like

- Enjoy fast sympathetic peer review and rapid publication of accepted articles

- Access all the published articles

Re-use any of the published material for personal use and teaching without further permission

Customer Service

If you have any further queries about your subscription, please contact our customer services team on +44 (0) 2071111105 or via email at support@bmj.com.

Visit casereports.bmj.com for more articles like this and to become a Fellow 